Nadia H Hasan BDS, MSc (Lec.)

\section{The Effect of Various Surface Treatment Adhesives and Composite Materials on Re- pair Strength of Composite Resin}

\author{
Dept of Conservative Dentistry
}

College of Dentistry, University of Mosul

\begin{abstract}
الحخلاصة
الأهداف: تمدف الدراسة الى تقييم تأثير مادةمركب بحموع الحفر والراتنج المتدفق على قوة الربط الانزلاقي لحشوه الاسنان البيضاء المرمه بانواع مختلفة من

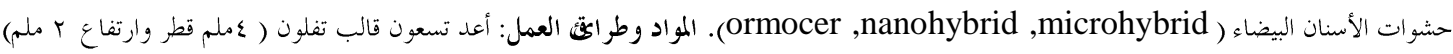

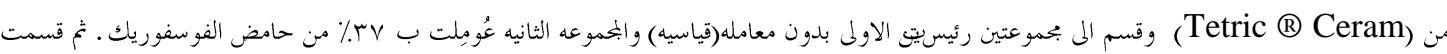

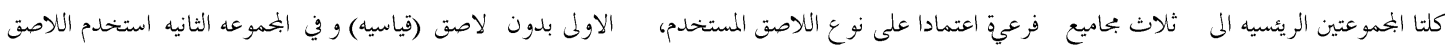

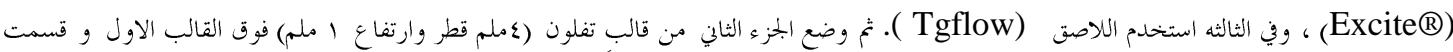

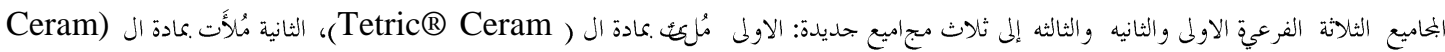

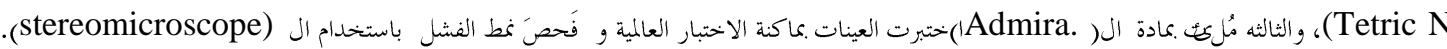

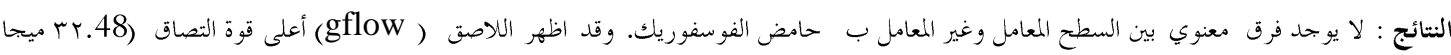

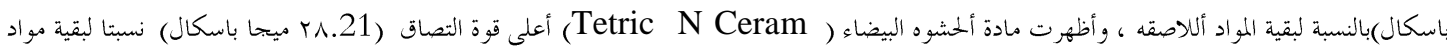

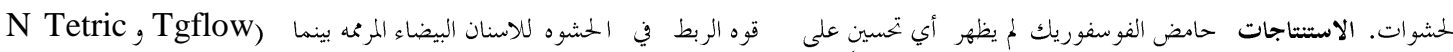

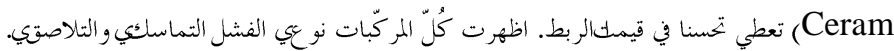

\begin{abstract}
Aims:of the study: The aim of this study is to evaluate the effect of a flowable composite and total etch adhesive on shear bond strength of repaired composite with a different types of tooth colored restorations (microhybrid, nanohybrid, and ormocer). Materials and Methods: Ninety Teflon mold (4 $\mathrm{mm} \times 2 \mathrm{~mm}$ ), of Tetric ${ }^{\circledR}$ Ceram prepared then divided into two main groups 1 st control ( without etching ), 2 ed etched with $37 \%$ phosphoric acid. Both groups were divided into three subgroups according to a type of adhesive applied, 1st control, 2 ed the Excite ${ }^{\circledR}$ and in 3 ed the tgflow applied.The second split of Teflon mold $(4 \mathrm{~mm} \times 1 \mathrm{~mm})$ placed onto the prepared specimen .Each subgroup (1st control, $2 \mathrm{ed}$ the Excite ${ }^{\circledR}$ and in 3rd the tgflow) were farther divided into three subgroups which entrain filled as fallow: 1st split filled with a Tetric ${ }^{\circledR}$ Ceram, in 2 ed split filled with Tetric N-Ceram, and in 3 rd. split filled with Admira. Shear bond strength was measured by using Universal Testing Machine, and mode of failure examined by a stereomicroscope. Results: No significant difference in the surface treatment groups. For the adhesive, Tgflow showed superior shear value (32.48 MPa) comparing to other adhesives while for the composite materials, The Tetric N-Ceram composite showed superior value of shear strength $(28.21 \mathrm{MPa})$ comparing to other materials. Conclusions: Phosphoric acid has no effect on shear value of repaired composite while Tgflow and Tetric N-Ceram give an improvement in its shear value .All composites exhibited cohesive and adhesive type of failure.
\end{abstract}

Key words: Significant Caries Index, DMFT, DMFS.

Hasan NH. The Effect of Various Surface Treatment Adhesives and Composite Materials on Repair Strength of Composite Resin. Al-Rafidain Dent J. 2012; 12(1): 126-134.

Received: 8/11/2010 Sent to Referees: 14/11/2010

Accepted for Publication: 28/11/2010

INTRODUCTION

A composite resin certainly come with a defect as a result of wear, fracture or discoloration after a long period of service, or may require small esthetic corrections a few days after restoration placement. $^{(1)}$ Unfortunately, complete removal of a failed composite restoration would gen- 
erally entail removal of previously etched enamel and subsequent etching of more enamel in order to optimize the enamel bond. ${ }^{(2)}$ Complete removal will therefore inevitably lead to larger cavities with further loss of tooth substance. On the basis of tooth saving principles, repair is an appropriate alternative of replacement of failed restorations and possibly increases the longevity of restorations at low cost, however some other factors like clinical situations, cost, esthetic, extent and mode of failure, failure site, quality of existing restoration, cause of failure and expected age of the existing restoration affect the treatment plan. ${ }^{(3)}$ Selective repair of the unsatisfactory part can be considered as more conservative approach than complete removal and remaking of the defective resin-based restoration. ${ }^{(4)}$

Bond strength of incrementally built up composite on fresh, uncontaminated or unprepared composite resin is similar to cohesive strength of the material. ${ }^{(5)}$ There is, however, a possibility of repair may lead to an unacceptably weak restoration . This potential problem has been investigated in several composite resin repair studies that have shown a wide variation in interfacial repair bond strengths equal 25$80 \%$ of the cohesive strength of the composite. ${ }^{(6)}$ It seems because of lack of airinhibited layer on surface, the degree of unreacted carbon double bond is lower and the chemical bonding between fresh and aged composite is not a reliable bond. ${ }^{(7)}$

Successful resin repair requires development of an adequate interfacial bond between the old and new resins various methods have been reported to improve the reactivity of highly converted compo- sites .These methods include acid etching, ${ }^{(8)}$ air abrasion, ${ }^{(9)}$ and the use of solvents and silanes. ${ }^{(2)}$ In addition, several studies have shown that the use of an intermediate bonding agent, ${ }^{(10,11)}$ repair material used, ${ }^{(12)}$ and time after repair, ${ }^{(11)}$ enhances the repair bond significantly .

In order to achieve long-lasting composite restorations, recent developments in polymer science have focused on reducing filler particle sizes and at the same time maximizing particle loading in composites, a nano-hybrid composite has conventional glass and innovative nano-scaled fillers. The reduction in particle size with such new resin composites has apparently opened a new gateway in restorative dentistry. Nano composites are claimed to combine the good mechanical strength of the hybrids and the superior polish of the microfills. ${ }^{(13,14)}$ In an attempt to overcome some of the limitations and concerns associated with the traditional composites, a new packable restorative material was introduced called ormocer which combines the surface properties of the silicones. The toughness of the organic polymers and the hardness and thermal stability of ceramics. ${ }^{(15)}$ Therefore, the objectives of this study is to evaluate the effect of a flowable composite and total etch adhesive on shear bond strength of repaired composite with a different types of tooth colored restorations (microhybrid, nanohybrid, and ormocer).

\section{MATERIALS AND METHODS}

The materials used in this study are listed in (Table 1) and were used strictly according to the manufacturer's recommendations.

Table (1): Materials used

\begin{tabular}{|c|c|c|}
\hline Material & Batch No. & Manufacturer \\
\hline Tetric $^{\otimes}$ Ceram & K00653 & Ivoclar vivadent \\
\hline Dental Restorative & & \\
\hline $\begin{array}{l}\text { Total Etch } \\
37 \% \text { phosphoric acid }\end{array}$ & K48227 & Ivoclar vivadent \\
\hline $\begin{array}{l}\text { Excite }^{\circledR} \text { Advanced Adhesive Technology } \\
\text { Universal Dental Adhesive }\end{array}$ & K43993 & Ivoclar vivadent \\
\hline $\begin{array}{l}\text { Tgflow } \\
\text { Flowable Light Cure Composite }\end{array}$ & 0510 & Technical \& General LTD, London, UK. \\
\hline Tetric N-Ceram & K09686 & Ivoclar vivadent \\
\hline $\begin{array}{l}\text { Admira (light- cured) } \text { Ormocer }^{\circledR} \text { based dental } \\
\text { restorative material }\end{array}$ & 811FGA1 & Technical \& General LTD, London, England \\
\hline
\end{tabular}


Ninety specimens of a light cured Tetric ${ }^{\circledR}$ Ceram composite, were prepared using a Teflon mold, the mold had a central hole measuring $(4 \mathrm{~mm})$ in diameter and $(2 \mathrm{~mm})$ in height. The mold was inserted on a glass slide and filled with a Tetric ${ }^{\circledR}$ Ceram using an incremental technique with a plastic instrument, covered with
Mylar strip and glass slide to produce a smooth surface and facilitate light curing, then cured with visible light source (Ivoclar vivadent. LED itian) for 40s from the top of the specimen with a standard light at $560 \mathrm{mw} / \mathrm{cm}^{2}$ assessed with a radiometer every 5 restorations (Figure $1 \mathrm{a}, \mathrm{b}$ and $\mathrm{c}$ ). a

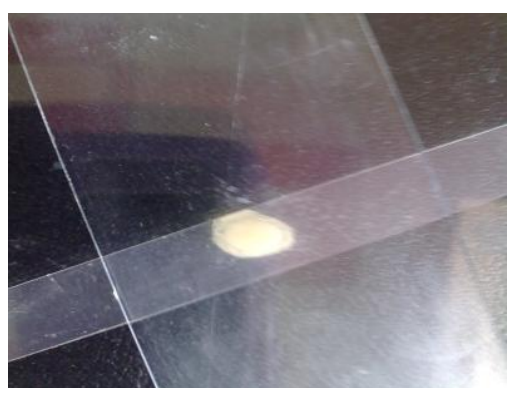

b

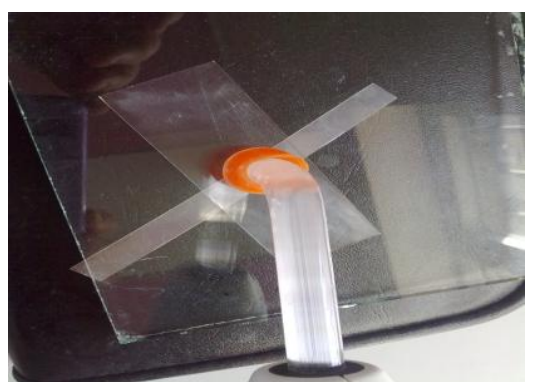

c

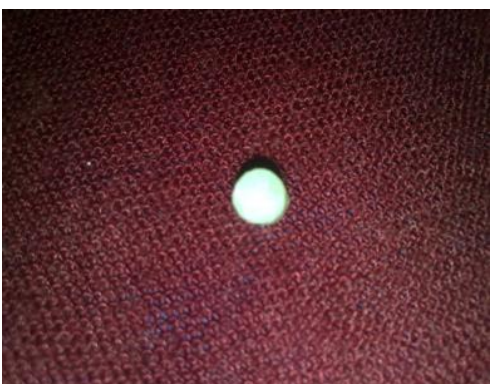

Figure 1: Steps for preparing sample

The samples were stored in distilled water at $37^{\circ} \mathrm{C}$ for $24 \mathrm{~h}$, thermo-cycled, to age the specimens of composite, for 300 cycles at temperature ranging from $5 \pm 2^{\circ} \mathrm{C}$ to $55 \pm 2^{\circ} \mathrm{C}$; each cycle lasted for $45 \mathrm{~s}$ with a dwell time of $15 \mathrm{~s}$, in each path, and $15 \mathrm{~s}$ intervals between paths.

The samples were randomly assigned to two groups $(n=45)$. In $1^{\text {st }}$ group (A1), the top surface Tetric ${ }^{\circledR}$ Ceram was remain intact (control) while the $2^{\text {ed }}$ (A2) group, the surface was etched for $15 \mathrm{~s}$ with $37 \%$ phosphoric acid etching gel, washed with water spry for $10 \mathrm{~s}$ and air dried for 10 s.

Both main groups $\left(1^{\text {st }}\right.$ and $\left.2^{\text {ed }}\right)$ were farther subdivided in three subgroups according to the type of adhesive material applied ( $\mathrm{n}=15),(\mathrm{B} 1, \mathrm{~B} 2$, and B3), and immediately further processed. In (B1) groups, the top surface of the Tetric ${ }^{\circledR} \mathrm{Ce}-$ ram, no adhesive was applied, (control). In (B2) groups, the Excite ${ }^{\circledR}$ (Advanced Adhesive Technology) was applied in a thin layer on the top surface of the composite using a micro-brush, gently air-thinned under compressed air and cured for 20s. Finally, in (B3) groups the tgflow (Flowable Light Cure Composite) was applied in a thin layer on the top surface of the com- posite using a micro-brush, gently airthinned under compressed air and cured for 20s.

For repair composite application, the second split of Teflon mold" (4mm in diameter and $1 \mathrm{~mm}$ in height)" was placed on to the prepared specimen. Each groups (B1,B2, and B3) farther subdivided into three subgroups $(\mathrm{n}=5),(\mathrm{C} 1, \mathrm{C} 2$, and $\mathrm{C} 3)$ .The second split of Teflon mold of (C1) group filled with a Tetric ${ }^{\circledR}$ Ceram was inserted into the mold incrementally, and cured for 40s. The (C2) group filled with Tetric N-Ceram, and cured for 40s. Finally, the (C3) group were filled with Admira and cured for 40s. After curing, specimens were gently removed from the Teflon molds and stored in distilled water at $37^{\circ} \mathrm{C}$ for $24 \mathrm{~h}$.

The bond strength between the light cured Tetric ${ }^{\circledR}$ Ceram composite and the repaired tooth colored restorations was measured by using Universal Testing Machine (Soil Test Co. Inc., ILL. USA) with a Knife edge head placed at the interface between the old and repaired composite at a cross head speed of $0.5 \mathrm{~mm} / \mathrm{min}^{(16)}$ (Figure $2 \mathrm{a}, \mathrm{b}$, and $\mathrm{c}$ ). 
a

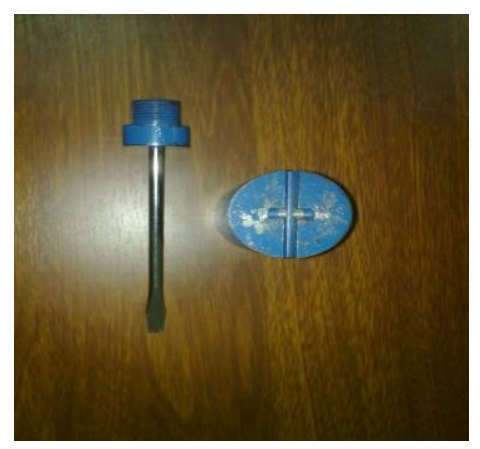

b

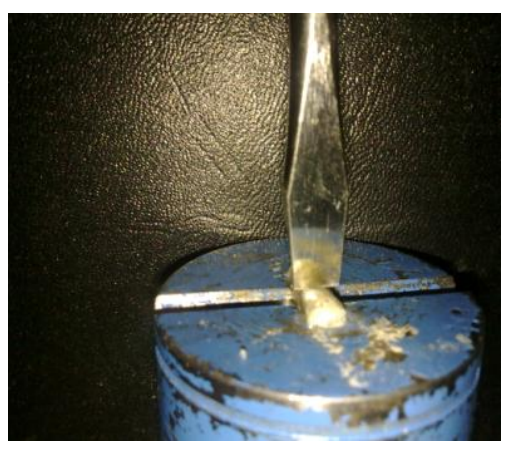

c

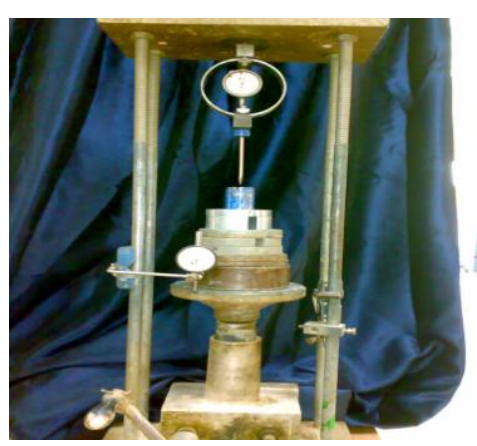

Figure 2: UniversalTestingMachine (SoilTest Co. Inc.,ILL. USA).

The modes of fracture were examined by a stereomicroscope (Zeiss, MC 63A, Germany) at $20 \mathrm{X}$ magnification power. Data were tabulated and statistically analyzed. They were analyzed using analysis of variance (ANOVA) followed by Duncan's Multiple Range Test at 1\%level of significance to indicate if there were any statistical difference in shear bond strength of all groups.

\section{RESULTS}

The mean and standard deviation of shear bond strength data obtained for all test groups are shown in (Table 2).

Table (2): Means and standard deviations of Surface treatment, Adhesives and Restorative Material

\begin{tabular}{|c|c|c|c|c|}
\hline \multirow[b]{2}{*}{$\begin{array}{l}\text { Surface treat- } \\
\text { ment }\end{array}$} & \multirow[b]{2}{*}{ Adhesive } & \multicolumn{3}{|c|}{ Restorative Material } \\
\hline & & $\begin{array}{l}\text { Tetric }^{\circledR} \text { Ceram } \\
\text { Mean } \pm \text { SD }\end{array}$ & $\begin{array}{l}\text { Tetric N-Ceram } \\
\text { Mean } \pm \text { SD }\end{array}$ & $\begin{array}{l}\text { Admira } \\
\text { Mean } \pm \text { SD }\end{array}$ \\
\hline \multirow{3}{*}{ control } & & $8.0008 \pm 3.688$ & $28.9645 \pm 16.4496$ & $7.9789 \pm 1.1998$ \\
\hline & Excite $^{\circledR}$ & $38.5829+1.0653$ & $53 \pm 9.8989$ & $18.2312+0.9696$ \\
\hline & Tgflow & $35.7411 \pm 15.3196$ & $26.1883 \pm 8.4188$ & $30.8226 \pm 5.2646$ \\
\hline \multirow{3}{*}{$\begin{array}{l}\text { Phosphoric } \\
\text { acid }\end{array}$} & control & $8.7003 \pm 0.3674$ & $22.0786 \pm 9.9996$ & $23.5214 \pm 20.7822$ \\
\hline & Excite $^{\circledR}$ & $9.6621 \pm 3.5464$ & $30.4947 \pm 3.2424$ & $12.3509 \pm 1.3161$ \\
\hline & Tgflow & $30.2549 \pm 0.7225$ & $36.4625 \pm 14.7686$ & $35.4132 \pm 7.5567$ \\
\hline
\end{tabular}

SD: Standard deviation.

Statistical analysis of data by using the analysis of variance "ANOVA" revealed that there was highly significant difference at $1 \%$ level of significe among the different subgroups for each group, but no significant difference revealed between the surface treatments groups (Table 3 ). 
Table (3): Mean square analysis for Surface treatment, Adhesives and Restorative Material

\begin{tabular}{lll}
\hline S.O.V. & d.f. & M.S. \\
\hline Surface treatment & 1 & $31.611^{\text {n.s }}$ \\
Adhesives & 2 & $1949.95^{* *}$ \\
Restorative Material & 2 & $438.22^{* *}$ \\
Interaction Between Surface treatment and Intermediate Adhesive & 2 & $417.59^{* *}$ \\
Interaction Between Surface treatment and Restorative Material & 2 & $574.44^{* *}$ \\
Interaction Between Adhesives and Restorative Material & 4 & $383.8^{* *}$ \\
Interaction Among Three Main Factors Surface treatment Adhesives, & & \\
and Restorative Material & 4 & $337.5^{* *}$ \\
Error & 72 & 86.20 \\
\hline Indicated not significant, $\quad * *$ Indicated highly significant differences at 1\% level, \\
d.f.: Degree of freedom; M.S.: Mean square; S.O.V.: Source of variance
\end{tabular}

Further investigation using Duncan's New Multiple Range Test" to revealed the differences in shear bond strength value of surface treatment, adhesives and restorative material. No significant difference showed between the surface treatment groups (control and phosophoric acid) (Figure 3). For the adhesive types the tgflow showed the highest shear value (32.48 MPa) in compare with total etch adhesive Excite ${ }^{\circledR}$ and the control one (Figure 4). For the restorative materials, the Tetric N-Ceram composite showed the highest shear value (28.21MPa) in compare with Tetric ${ }^{\circledR}$ Ceram and Admira (Figure 5).

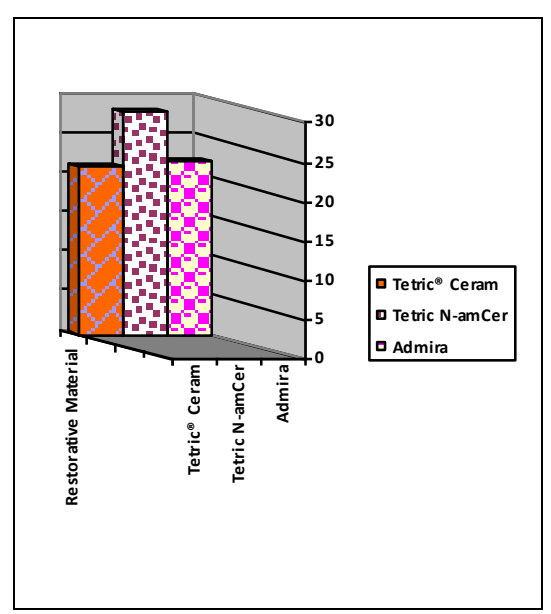

Figure 3: a histogram representing the mean of shear bond strength of the surface treatment groups.

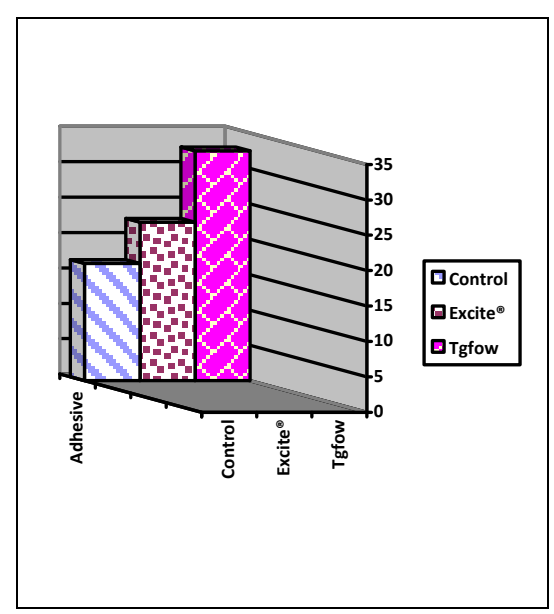

Figure 4: a histogram representin€ the mean of shear bond strength $c$ the adhesives

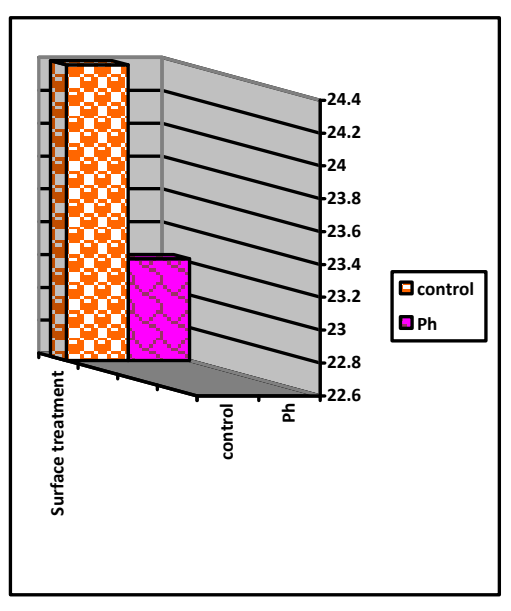

Figure 5: a histogram representing the mean of shear bond strength of the restorative material.
For the interaction between the tgflow and the total etch adhesive Excite $^{\circledR,}$ showed a high shear value when used without surface treatment group and with the phosphoric acid (for the tgflow) in compare with others. The Tetric N-Ceram and Tetric ${ }^{\circledR}$ Ceram showed a high shear value when used without surface treatment and with the phosphoric acid (for the Tetric N-Ceram) in compare with others. 
The tgflow had high shear value with all types of restorative material while adhesive Excite ${ }^{\circledR}$ had the same shear value with both Tetric N-Ceram and Tetric ${ }^{\circledR}$ Ceram only, and the control group of adhesive has the same shear value with Tetric $\mathrm{N}$ Ceram in compare with others (Table 4).

Table (4): Duncan's New Multiple Range Test for variables.

\begin{tabular}{|c|c|c|c|c|c|c|c|c|c|c|}
\hline \multirow[b]{2}{*}{ 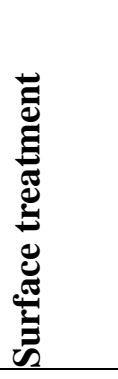 } & \multirow{2}{*}{ 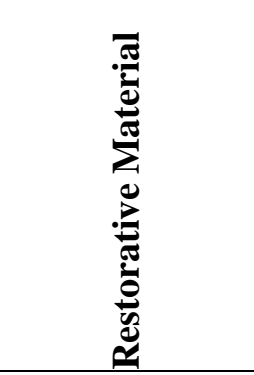 } & \multicolumn{6}{|c|}{ Adhesive } & \multirow[b]{2}{*}{ 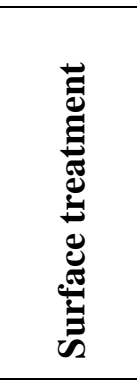 } & \multirow{8}{*}{ 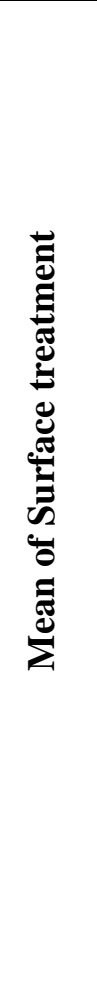 } & \\
\hline & & 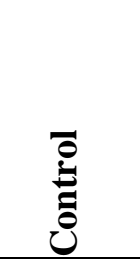 & 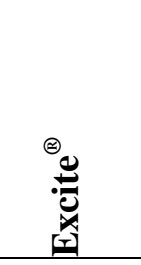 & $e_{0}^{\frac{B}{60}}$ & 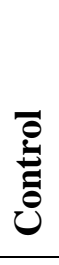 & 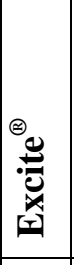 & $\frac{\vec{a}}{e_{0}^{2}}$ & & & 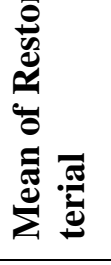 \\
\hline \multirow{3}{*}{$\begin{array}{l}\overline{0} \\
\stackrel{\Xi}{0} \\
0\end{array}$} & Tetric $^{\circledR}$ Ceram & $8.0^{g}$ & $38.58^{\mathrm{a}}$ & $35.74^{\mathrm{abc}}$ & $\begin{array}{l}i n \\
\dddot{n} \\
\infty\end{array}$ & $\begin{array}{l}\stackrel{a}{\sim} \\
\stackrel{\sim}{\sim}\end{array}$ & $\begin{array}{l}\tilde{a} \\
\dot{m} \\
m\end{array}$ & $27.44^{\mathrm{a}}$ & & $21.39^{\mathrm{b}}$ \\
\hline & Tetric N-amCer & $28.97^{\mathrm{a}-\mathrm{d}}$ & $25.1^{\mathrm{a}-\mathrm{e}}$ & $26.19^{\mathrm{a}-\mathrm{d}}$ & 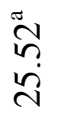 & $\begin{array}{l}\tilde{0} \\
\infty \\
\dot{\sim}\end{array}$ & $\frac{\tilde{m}}{m}$ & $26.75^{\mathrm{a}}$ & & $28.21^{\mathrm{a}}$ \\
\hline & Admira & $7.98^{g}$ & $18.23^{\mathrm{d}-\mathrm{g}}$ & $30.82^{\mathrm{a}-\mathrm{d}}$ & $\begin{array}{l}\text { in } \\
i n \\
i n\end{array}$ & $\begin{array}{l}\stackrel{0}{2} \\
\stackrel{1}{2}\end{array}$ & $\stackrel{\stackrel{a}{7}}{\stackrel{m}{m}}$ & $19.01^{\mathrm{bc}}$ & & $21.82^{b}$ \\
\hline \multirow{3}{*}{$\frac{\tau}{Q}$} & Tetric $^{\circledR}$ Ceram & $8.70^{\mathrm{g}}$ & $9.66^{\mathrm{fg}}$ & $30.25^{\mathrm{a}-\mathrm{d}}$ & & & & $16.21^{\mathrm{c}}$ & & \\
\hline & Tetric N-Ceram & $22.08^{\mathrm{c}-\mathrm{f}}$ & $30.50^{\mathrm{a}-\mathrm{d}}$ & $36.46^{\mathrm{ab}}$ & & & & $29.68^{\mathrm{a}}$ & & \\
\hline & Admira & $23.52^{\mathrm{b}-\mathrm{e}}$ & $12.35^{\mathrm{fg}}$ & $35.41^{\mathrm{abc}}$ & & & & $23.76^{\mathrm{ab}}$ & & \\
\hline control & & $14.98^{\mathrm{b}}$ & $27.30^{\mathrm{a}}$ & $30.92^{\mathrm{a}}$ & & & & & 24.40 & \\
\hline $\mathrm{Ph}$ & & $18.10^{\mathrm{b}}$ & $17.50^{\mathrm{b}}$ & $34.04^{\mathrm{a}}$ & & & & & 23.22 & \\
\hline \multicolumn{2}{|c|}{ Mean of Adhesive } & $16.54^{\mathrm{c}}$ & $22.40^{\mathrm{b}}$ & $32.48^{\mathrm{a}}$ & & & & & & \\
\hline
\end{tabular}

Different letters indicate significant differences, PH :Phosphoric acid.

Failure types of all composite were cohesive in both control and etched groups in between $(23 \%-74 \%)$ in the repairing resin. Tetric ${ }^{\circledR}$ Ceram composite and Admi- ra exhibit adhesive failures in between (40\%-54\%) in comparing to the Tetric NCeram (10\%- 24\%), (Table 5).

Table (5): Type of failure between the Surface treatment and different tooth-colored restorative materials.

\begin{tabular}{|c|c|c|c|c|c|c|c|c|}
\hline \multirow{4}{*}{ Restorative Material } & \multicolumn{8}{|c|}{ Surface treatment } \\
\hline & \multicolumn{4}{|c|}{ Control } & \multicolumn{4}{|c|}{$\mathrm{Ph}$} \\
\hline & \multicolumn{4}{|c|}{ Type of testing } & \multicolumn{4}{|c|}{ Type of testing } \\
\hline & A & $\mathrm{CR}$ & $\mathrm{CS}$ & $\mathrm{M}$ & A & $\overline{\mathrm{CR}}$ & CS & $\mathrm{M}$ \\
\hline Tetric $^{\circledR}$ Ceram & $40 \%$ & $24 \%$ & $0 \%$ & $36 \%$ & $54 \%$ & $47 \%$ & $0 \%$ & $0 \%$ \\
\hline Tetric N-Ceram & $24 \%$ & $50 \%$ & $12 \%$ & $14 \%$ & $10 \%$ & $74 \%$ & $0 \%$ & $6 \%$ \\
\hline Admira & $44 \%$ & $23 \%$ & $16 \%$ & $17 \%$ & $54 \%$ & $46 \%$ & $0 \%$ & $0 \%$ \\
\hline
\end{tabular}

Ph: Phosphoric acid; A: adhesive; CR: cohesive in the repairing resin; CS: cohesive in the substrate; M: mixed 


\section{DISCUSSION}

There are many problems in repair of aged composite resin restorations. Because there is no air-inhibited layer and degree of conversion is high ${ }^{(7,17)}$ and because of leaching of non- reacted monomers even though in minor amounts ${ }^{(18)}$. There is a reduction in number of unsaturated double bonds for producing the initial and secondary bonds between the new and old composite. Meanwhile with increasing polymerization, there is decreasing in solubility and permeability of polymer and in order to obtain a good adhesion between the aged and repaired part of composite restorative material, a roughened surface and intermediated adhesive bonding is needed for repairing composite. Increasing the surface roughness provides better mechanical interlocking and increases the probability of finding residual free carbon bonds through the treatment and bonding agent varied widely. ${ }^{(18)}$ The use of phosphoric acid provided unacceptable weakest repair bond strength in both microhybrid and micro filled composites surface. ${ }^{(19)}$ In our study, no significant difference on shear bond value between control and phosphoric acid groups was found which came in agreement with different studies. ${ }^{(20-22)}$ Other studies showed that the acid etching did not change the morphology of the composite surface and it seemed to exert only a cleaning effect, without contributing to composite to- composite micromechanical adhesion. ${ }^{(20,23)}$

In vitro studies on aged composites have indicated that the repair bond strength increases after the application of an intermediate adhesive resin. ${ }^{(10,11)}$ Our finding showed the same result when the tgflow as an intermediate adhesive resins applied on an old composite surfaces, significant improvement was found on shear value in compare with Excite ${ }^{\circledR}$ and control group which agreed with several studies. ${ }^{(24)}$ However, the use of a flowable composite resin has been shown to be a reliable method of repair for composite restorations due to its flowability. ${ }^{(25)}$ The filler level in a composite material determines its mechanical strength and physical properties. Flowable composite adhesive material and an overlying hybrid composite material can combine the advantages of each material to provide better marginal adaptation, mechanical strength, stress reduction, and wear resistance in operative dentistry. These materials may provide an intermediate elastic layer between the repair composite and the based layer, which may absorb the stress arising from occlusal forces and enhance increase the shear bond strength and durability of the repair. ${ }^{(26)}$

The significant differences between bond strengths of the different composites in comparing to the control group may be related to noticeable differences in filler size and shape among the different materials, ${ }^{(27)}$ as well as the size of its particles contribute to the bond strength when re layering or repair is performed. ${ }^{(10,28)}$

The cohesive types of failure of all composites were in both control and etched groups seemed to be a typical finding and may be because composite contains numerous air inclusions. These air inclusions can act as stress points, thus giving rise to the increased likelihood of cohesive failure within the composite. ${ }^{(29)}$ The higher adhesive percentage types of failure of Tetric ${ }^{\circledR}$ Ceram composite and Admira in comparing to the Tetric NCeram after intermediate adhesive resin application could be a consequence of its resin matrix composition. Söderholm ${ }^{(30)}$ argued that the unfilled resin cannot chemically react without a coupling agent. So, the only possibility of chemical bonding with the composite is by bonding with the residual monomers in the substrate. The better results of Tetric N-Ceram are explained by the higher proportion of resin in a Nano-hybrid composite.

\section{CONCLUSION}

With the limitation of this in vitro study, phosphoric acid has no effect on shear value of repaired composite. Using the tgflow, as an intermediate adhesive, give improvement on shear value for the repaired composite due to its flowability and repairing the aged composite with Tetric N-Ceram composite gives beast shear strength due to its filler size, shape, as well as the small size of its particles. 


\section{REFERENCES}

1. Krejci I, Lieber CM, Lutz F. Time required to remove totally bonded toothcolored posterior restorations and related tooth substance loss. Dent Mater.1995; 11:34-40.

2. Soderholm K-JM, Roberts MJ. Variables influencing the repair strength of dental composites. Scand J Dent Res. 1991; $99: 173-80$.

3. Mjor IA. Repair versus replacement of failed restorations. Int Dent J. 1993; $43: 466-72$.

4. Gordan VV, Shen C, Riley J 3rd, Mjor IA .2-year clinical evaluation of repair versus replacement of composite restorations.J Esthet Restor . 2006; 18: 144-53.

5. Boyer DB, Chan KC, Torney DL .The strength of multilayer and repaired composite resin. J Prosthet Dent .1978; 39: 63-67.

6. Turner CW, Meiers JC. Repair of an aged contaminated indirect composite resin with a direct visible light -cured composite resin . Oper Dent. 1993; 18 : 187-94.

7. Craig RG. Powers JM. Restorative Dental Materials.11th ed .USA: Mosby; 2002.

8. Swift Jr, LeValley BD, BoyerDB. Evaluation of new method s for composite repair.Dent Mat.1992; 8:36265.

9. Causton BE .Repair of an abraded composite fillings .An in vitro study. Br Dent J .1975; 139:286-88.

10. Shahdad SA, Kennedy JG. Bond strength of repaired anterior composite resins: an in vitro study.J Dent .1998; 26:685-94.

11. Papacchini F, De Castro FLA, Goracci C, Sardella TN, Tay FR, Polimeni A, Ferrari M, Carvalho RM .An investigation of the contribution of saline to the composite repair strength over time using a double -sided microtensile test .Int Dent South Africa.2006; 8:26-36.

12. Brendeke J, Ozcan M .Effect of psysicochemical aging conditions on the composite-composite repair bond strength. J Adhes Dent. 2007; 9:393406 .

13. Moszner N, Salz U. New develop- ments of polymeric dental composites. Prog Polym Sci . 2001; 26: 535-576.

14. Mitra SB, Wu D, Holmes B. An application of nanotechnology in advanced dental materials. J Am Dent Assoc. 2003; 134: 1382-90.

15. Sivakumar A, Valiathan A. Dental Ceramics and Ormocer Technology Navigating the Future! Trends Biomater . Artif Organs.2006; 20(1): 40-43.

16. Ribeirao P. Effect of refrigeration on bond strength of self -etching adhesive systems. Braz Dent J.2006; 17(3).

17. Ruyter E, Svendsen SA .Remaining methacrylate group in composite restoratives materials. Acta odontol Scand. 1977; $36: 75-82$.

18. Ferracane JL. Elution of leach able components from composite. J Oral Rehabil .1994; 21 :441-52.

19. Nilsoon E, Alaeddin S .Factors affecting the shear bond strength of bonded composite inlays . Int J Prosthodont. 2000; $13: 52-58$.

20. El-Askary FS, Fawzy AS, Abd Elmohsen HM. Tensile bond strength of immediately repaired anterior microfine hybrid restorative composite using non trimmed hourglass specimens. $J$ Adhes Dent. 2009 Feb; 11(1):41-7.

21. Nadia M T, Nasrien Z A. Shear bond strength of resin modified glass ionomer cement bonded to different toothcolored restorative materials. $J$ Contemp Dent Pract. 2007 Feb 1; 8(2):2534.

22. Susanna DO, Federica P, Ivana R, Antonella P, Marco F. Repair potential of a laboratory processed nano-hybrid resin composite. J Oral Sc.2008;50 (4):403-12.

23. Papacchini F, Radovic I, Magni E, Goracci C, Monticelli F, Chieffi N, Polimeni A, Ferrari M. Flowable composites as intermediate agents without adhesive application in resin composite repair. Am J Dent. 2008 Feb; 21(1):53-8.

24. Nuray C, Ahmet U, Ender K, Senih C.Effect of Flowable Composite Intermediate Layer on Bond Strength of Intra-Oral Porcelain Repair :An In-Vitro Study. OHDMBSC.2009; 8(2): 3843.

25. Haffe MS, Lindemuth JS, Jones 
AG.Shear bond strength of bis-acryl composite provisional material repaired with flowable composite.$J E s$ thet Dent. 2002; 14:47-52.

26. Tung FF, Estafan D, Scherer W .Microleakage of condensable resin composite :An in vitro investigation. Quint Int. 2000; $31: 430-34$.

27. Moraes RR, Gonçalves LS, Lancellotti AC, Consani S,Correr-Sobrinho L, Sinhoreti MA. Nanohybrid Resin Composites: Nanofiller Loaded Materials or Traditional Microhybrid Resins. Oper Dent.2009; 34(5):551-7.

28. Yesilyurt C, Kusgoz A, Bayram M,
Ulker M. Initial repair bond strength of a nano-filled hybrid resin: effect of surface treatments and bonding agents. J Esthet Restor Dent. 2009; 21(4):25160.

29. Burrow MF, Nophakeepong U, Phrukkanon S: A comparison of microtensile bond strengths of several dentin bonding systems to primary and permanent dentin. Dent-Mat. 2002; 18: 239-245.

30. Söderholm KJ .Flexure strength of repaired dental composites. Scand J Dent Res. 1986; 94:364-9. 